\title{
Concentration of three branched-chain fatty acids in adipose tissue does not affect meat sensory traits in crossbred and purebred German "Merinolandschaf" lambs
}

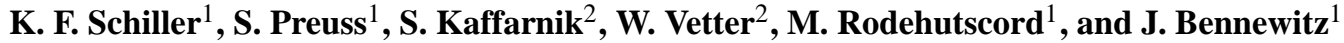 \\ ${ }^{1}$ Institute of Animal Science, University of Hohenheim, Stuttgart, Germany \\ ${ }^{2}$ Institute of Food Chemistry, University of Hohenheim, Stuttgart, Germany
}

Correspondence to: K. F. Schiller (katja.schiller@uni-hohenheim.de)

Received: 8 January 2015 - Revised: 13 March 2015 - Accepted: 30 March 2015 - Published: 24 April 2015

\begin{abstract}
Intense sheep odour and flavour in lamb is often associated with lower consumer acceptance. Branched-chain fatty acids (BCFAs) are suggested as possible reasons. Therefore, muscle and subcutaneous adipose tissue samples of 98 lamb chops were analysed for three BCFAs (4-methyloctanoic, 4-ethyloctanoic and 4-methylnonanoic fatty acid). Samples were derived from a previous study, in which lambs were raised and fattened under intensive conditions and tested for sensory quality. BCFA contents of fat extracts from muscle tissue were very low and quantification was not possible. In subcutaneous adipose tissue different concentrations of BCFA and differences between crosses were detected. The sex of lambs had a significant influence. The BCFA correlations were significant, while correlations between BCFA of adipose tissue and sensory traits were not significant. Therefore, it seems likely that BCFA concentrations were too low and/or other substances are involved in causing the lamb flavour detected through sensory analysis.
\end{abstract}

1

"Merinolandschaf" (ML) represent a widespread sheep breed in Germany. In order to improve growth performance of fattening lambs, F1-crossbreeding obtained from mating ML ewes with a meat-type terminal-sire breed is frequently performed. The choice of the sire line is of fundamental importance for optimizing F1-crossing systems to provide the best possible quality.

Typical sheep odour and flavour is often associated with an unpleasant smell and therefore lower consumer acceptance of sheep products such as lamb (Prescott et al., 2001; Rhee and Ziprin, 1996; Wong et al., 1975). For lamb production, choosing a certain terminal-sire breed would be a rather simple and practicable opportunity to achieve better consumer acceptance if this reduced species-specific odour and flavour. In the sensory analysis of Henseler et al. (2014), differences in lamb flavour between crosses were detected. Since feeding conditions were comparable for the crosses, a genetic influence of crossing was assumed. The branchedchain fatty acids (BCFAs) 4-methyloctanoic acid (4-Me-8:0), 4-methylnonanoic acid (4-Me-9:0) (Wong et al., 1975) and 4-ethyloctanoic acid (4-Et-8:0) (Ha and Lindsay, 1990) were thought to be mainly responsible for species-related flavour. Prescott et al. (2001) mentioned 4-Me-8:0, in particular, as a strong candidate. The authors reported that an increase in BCFA content in meat, reached by adding different amounts of 4-Me-8:0 and 4-Me-9:0, resulted in decreased acceptance of the meat on the part of consumers. As medium-chain fatty acids might have a more decisive role than longer chained fatty acids in sensory analysis, due to their higher volatility, we focused on three medium-sized BCFAs, namely 4-Me8:0, 4-Me-9:0 and 4-Et-8:0.

Feed was found to have a strong impact on the concentrations of BCFA in lamb tissue. According to Duncan and Garton (1978), carbohydrate-rich feed (barley-based) results in higher BCFA concentrations in subcutaneous adipose tissue than grass feeding. Busboom et al. (1981) reported higher 
Table 1. Crosses, cross abbreviations (abbrev.), number $(n)$ of muscle tissue samples (MEAT), number of subcutaneous adipose tissue samples (FAT) per cross and sex and concentrations of 4-Me-8:0, 4-Et-8:0 and 4-Me-9:0 (ng mg ${ }^{-1}$ ) in subcutaneous adipose tissue of different crosses of sheep.

\begin{tabular}{|c|c|c|c|c|c|c|c|c|c|}
\hline Cross/sex & abbrev. & \multicolumn{2}{|c|}{$n$} & \multicolumn{2}{|c|}{ 4-Me-8:0 (ng mg $\left.{ }^{-1}\right)$} & \multicolumn{2}{|c|}{ 4-Et-8:0 (ng mg $\left.{ }^{-1}\right)$} & \multicolumn{2}{|c|}{ 4-Me-9:0 (ng mg $\left.{ }^{-1}\right)$} \\
\hline Charolais $\times \mathrm{ML}^{*}$ & $\mathrm{CH}$ & 4 & 14 & $103.0^{\mathrm{c}}$ & 13.1 & $19.7^{\mathrm{b}}$ & 2.3 & $46.6^{\mathrm{b}}$ & 9.3 \\
\hline $\mathrm{ML} \times \mathrm{ML}$ & ML & 3 & 15 & $57.3^{\mathrm{a}}$ & 12.7 & $15.4^{\mathrm{a}, \mathrm{b}}$ & 2.3 & $18.3^{\mathrm{a}}$ & 9.0 \\
\hline German blackheaded mutton sheep ${ }^{* *} \times$ ML & SK & 2 & 18 & $99.1^{\mathrm{b}, \mathrm{c}}$ & 11.6 & $18.4^{\mathrm{a}, \mathrm{b}}$ & 2.1 & $44.6^{\mathrm{b}}$ & 8.3 \\
\hline Male & $\mathrm{m}$ & 8 & 44 & $99.7^{\mathrm{a}}$ & 7.4 & $15.5^{\mathrm{a}}$ & 1.3 & $48.5^{\mathrm{a}}$ & 5.3 \\
\hline Female & $\mathrm{f}$ & 9 & 54 & $57.3^{b}$ & 6.7 & $18.3^{\mathrm{a}}$ & 1.2 & $15.6^{\mathrm{b}}$ & 4.8 \\
\hline
\end{tabular}

* ML is "Merinolandschaf"; ** German blackheaded mutton sheep is "Deutsches Schwarzköpfiges Fleischschaf"; a,b,c,d within a column and same effect (cross or sex), values with different superscript letters (a-d) differ significantly at $P \leq 0.05$.

BCFA concentrations for high- compared to low-energy diets. For pasture feeding, lower concentrations of 4-Me-8:0 and 4-Me-9:0 were reported compared to concentrate feeding (Priolo et al., 2001; Young et al., 2003). Similar results were reported for other BCFAs, such as 4-Me-10:0, 4-Me12:0 and 4-Me-14:0 (Miller et al., 1986), even though only low amounts of BCFA could be found in plants (Diedrich and Henschel, 1990). BCFAs are formed mainly from microbial metabolism in the rumen (Chilliard et al., 2003). Through this fermentation, acetate, propionate and butyrate are produced, and, especially at high propionate concentrations, BCFA formation increases (Lindsay, 1996).

The aim of the present study was to investigate the occurrence and concentrations of the branched-chain fatty acids 4-Me-8:0, 4-Me-9:0 and 4-Et-8:0 in five different F1crossbreeds and purebred ML. Intense feeding conditions were chosen because BCFA concentrations were expected to be higher than for pasture feeding and feeding differences could be minimized. A further aim was to investigate the relationship between the branched-chain fatty acids tested and several sensory traits.

\section{Material and methods}

\subsection{Animals and sensory data set}

The tissues analysed were from chops of the 10/11th rib obtained from 98 lambs. All lambs were purebred ML or F1-crossbred lambs which were produced to test five meattype terminal-sire breeds (Charolais, Ile de France, German blackheaded mutton sheep, Suffolk and Texel) on ML ewes. Crosses and cross abbreviations are listed in Table 1. Intensive feeding conditions were chosen. Lambs were raised on seven farms until weaning at a body weight (BW) of $17 \mathrm{~kg}$ with free access to concentrate (soy- and barley-based) and roughage. Fattening was centralized and took place in group housing with $200-300 \mathrm{~g}$ hay day ${ }^{-1}$ per animal and concen- trate ad libitum. Lambs were slaughtered at $43.14 \pm 3.78 \mathrm{~kg}$ body weight and at an age of 102-161 days. After slaughter the carcasses were chilled to $1-3{ }^{\circ} \mathrm{C}$ and dissected; adipose and muscle tissue of the chops were separated and frozen $\left(-20^{\circ} \mathrm{C}\right) 48 \mathrm{~h}$ post mortem. To ensure enough sample material for analysis, lambs needed to weigh at least $36 \mathrm{~kg}$ at slaughter and show medium fat coverage. Lambs were chosen at random from animals fulfilling these criteria. All samples were homogenized after 222-530 days of storage (disperser Ultra Turrax T18-10, IKA Werke, Staufen, Germany), and muscle tissue was lyophilized (freeze dryer Gamma 120 LMC2, Martin Christ, Osterode, Germany) at 2.6 mbar for $72 \mathrm{~h}$. Samples were frozen $\left(-20^{\circ} \mathrm{C}\right)$ until preparation for analysis.

In a previous study, chops of the same animals as used for this study were tested for their sensory meat quality (Henseler et al., 2014). The traits tested were overall appraisal, lamb flavour, flavour quality, odour, juiciness and tenderness. Traits were evaluated by a trained sensory panel of 21 persons of different sex and ages. Fifteen sensory tests were conducted on 15 days; a duplicate was included in every test for every tester. The chops tested were $2 \mathrm{~cm}$ thick and unseasoned, and subcutaneous fat was removed. They were grilled on a contact grill at $170^{\circ} \mathrm{C}$ and subsequently left to simmer for 2:20 min wrapped in aluminium foil. For tasting, the chops were sliced in $0.7 \mathrm{~cm}$ broad sections, and the inner and outer sections were discarded. The data set of the sensory analysis was used for determining possible relations between BCFA concentrations and sensory traits.

\subsection{Analysis of BCFA}

The fat extracts of raw muscle tissue of musculus longissimus thoracis et lumborum and subcutaneous adipose tissue of the same chop (without bones) were analysed separately. The preparation of the samples was undertaken according to the method of Kaffarnik et al. (2014). Subcutaneous fat sam- 
ples were directly transesterified to result in fatty acid methyl esters (FAMEs).

The fat of muscle tissue samples (dried homogenized muscle tissue, subcutaneous fat removed) was extracted by means of a Soxtherm apparatus (Kaffarnik et al., 2014). The sample extracts were concentrated to $10 \mathrm{~mL}$, and an aliquot was used for the formation of FAMEs. FAMEs were analysed by gas chromatography coupled with mass spectrometry in selected ion monitoring mode (GC-MS-SIM). Quantification was performed using the internal standards undecenoic acid methyl ester $(11: 1 n-1)$ and tetradecanoic acid ethyl ester (14:0). The limit of detection was $1.1-1.4 \mathrm{ng} \mathrm{g}^{-1}$, and the limit of quantification was 3.6-4.8 pg (Kaffarnik et al., 2014).

Additionally, it was tested whether lyophilization had any influence on the results. For this purpose, $1.43 \mathrm{~g}$ fresh muscle tissue was pulverized and mixed with sodium sulfate (ratio $2.6: 1$ ); the remaining procedure was as described above. For another test three adipose tissue samples were lyophilized. The dry samples and their condensates, derived from the drying process, were directly esterified and analysed.

\subsection{Statistical analysis}

The concentrations of BCFA found were recorded for each chop and analysed using the following statistical model:

$y_{i j k}=\mu+C_{j}+\mathrm{SEX}_{k}+C_{j} \cdot \mathrm{SEX}_{k}+e_{i j k}$,

where $y_{\ldots}$ is the amount of BCFA of lamb $i\left(\mathrm{ng} \mathrm{mg}^{-1}\right), C_{j}$ is the fixed effect of cross $j$ and $\operatorname{SEX}_{k}$ is the fixed effect of sex $k$. $C_{j} \cdot \mathrm{SEX}_{k}$ represents the interaction of cross $j$ and $\mathrm{SEX}_{k}$. The model was fitted using the MIXED procedure of SAS (9.2, SAS Inst. Inc., Cary, NC). For the calculation of correlation, data of subcutaneous adipose tissue and the sensory analysis from Henseler et al. (2014) were used.

\section{Results}

\subsection{Muscle tissue}

Muscle tissue samples from 17 lambs showed concentrations below the limit of quantification or below the limit of detection for all three BCFAs investigated (data not shown). This was also valid for the non-lyophilized fresh muscle tissue tested. Due to these results the amount of samples was limited to 17 because a sample with BCFA sufficient for quantification was not expected to be found. Losses in BCFA concentration arising from lyophilization under the conditions applied were not detectable. In collected fatty condensates, developed during lyophilization, no BCFAs were detectable.

\subsection{Adipose tissue}

Significant differences between crosses were detected for all three fatty acids tested (shown in Table 1). Concentrations of 4-Me-8:0 ranged between 56.9 and $103.0 \mathrm{ng} \mathrm{mg}^{-1}$,
Table 2. Correlation coefficients of concentrations of the fatty acids 4-Me-8:0, 4-Et-8:0 and 4-Me-9:0 (ng mg $\left.{ }^{-1}\right)$ in sheep subcutaneous adipose tissue and six sensory traits (Henseler et al., 2014).

\begin{tabular}{lrrr}
\hline & 4-Me-8:0 & 4-Et-8:0 & 4-Me-9:0 \\
\hline 4-Me-8:0 & 1 & & \\
4-Et-8:0 & $0.335^{*}$ & 1 & \\
4-Me-9:0 & $0.878^{*}$ & 0.080 & 1 \\
\hline Overall appraisal & -0.156 & -0.044 & -0.045 \\
Lamb flavour & -0.005 & 0.072 & -0.073 \\
Flavour quality & -0.088 & -0.058 & -0.026 \\
Odour & -0.104 & -0.060 & -0.012 \\
Juiciness & 0.034 & -0.097 & 0.128 \\
Tenderness & -0.189 & 0.037 & -0.144 \\
\hline
\end{tabular}

* Significant at $P \leq 0.01$.

while those of 4-Et-8:0 (13.3-19.7 $\left.\mathrm{ng} \mathrm{mg}^{-1}\right)$ and for 4Me-9:0 (17.3-46.6 $\mathrm{ng} \mathrm{mg}^{-1}$ ) were lower. Only CH and SK showed significant differences in 4-Me-8:0 and 4-Me-9:0 concentrations compared to ML. For 4-Me-9:0, two groups were distinguishable, with $\mathrm{CH}$, SK and SU having significantly higher values. For 4-Et-8:0, none of the crosses tested showed significant differences compared to purebred ML. A significant $(P \leq 0.001)$ influence of sex was identified for concentrations of 4-Me-8:0 and 4-Me-9:0 but not for 4-Et8:0 (Table 1). The cross-sex interaction effect was significant for 4-Me-8:0 and 4-Me-9:0 at $P \leq 0.05$. These interaction effects resulted in scaling effects, i.e. the differences between the crosses and between sexes varied numerically but without a re-ranking. For 4-Et-8:0, the interaction effect was not significant.

\subsection{Correlations of BCFA concentrations and sensory analysis}

Significant $(P \leq 0.01)$ correlations were detected between the BCFAs tested (see Table 2), indicating, in particular, that concentrations of 4-Me-8:0 and 4-Me-9:0 are closely related. Correlations between the amounts of BCFAs in adipose tissue and the sensory traits were not significant.

\section{Discussion}

The quantification of the fat extracts of muscle tissue (MEAT) samples turned out to be more problematic than for subcutaneous adipose tissue (FAT). Quantification for MEAT was not possible, while for corresponding FAT from the same individual quantification was possible. FAT samples showed analysable results despite the concentration of injection being lower than for MEAT. Brennand and Lindsay (1992) reported higher concentrations of 4-Me-8:0, 4-Et-8:0 and 4Me-9:0 in FAT than in MEAT, which supports the results of the present study. Miller et al. (1986) reported lower levels 
of other BCFAs (4-Me-10:0, 4-Me-12:0 and 4-Me-14:0) in MEAT than in FAT, partly below the limit of quantification.

For all three BCFAs, significant differences between specific crosses were detected. The smallest differences were detected for 4-Et-8:0. Busboom et al. (1981) tested several BCFAs (4-Me-10:0 until 4-Me-17:0 and 4-Me-17:1) and reported small and nonsignificant breed effects. Also, Duckett and Kuber (2001) determined that breed or the breed of terminal sire seems to have a minor impact on the intensity of lamb flavour. Apart from the detected breed effects in the present study, a highly significant $(P \leq 0.001)$ influence of sex was detected for two of the BCFAs investigated (Table 1). This is supported by results in Watkins et al. (2010), who detected influences of sex and age for 4-Me-8:0, 4-Et-8:0 and 4-Me-9:0. The influence of age at slaughter was tested but was not significant in the present study, most likely because age variation was low.

As summarized by Young and Braggins (1998), it seems probable that other substances, such as phenols and sulfurcontaining compounds, could play a role besides BCFA for the lamb or sheep-like odour and flavour. According to Resconi et al. (2010), lamb flavour in grilled loins is related to the concentration of heptan-2-one and oct-1-en-3-one. Priolo et al. (2001) suggested that 3-methylindole (skatole), in addition to its own flavour, might increase the perception of sheep-like flavour caused by BCFA. Another factor might be the concentration of linoleic and $\alpha$-linolenic acid, which, according to Sañudo et al. (2000), influence lamb flavour intensity. The presence of some of the substances mentioned might explain the results of Henseler et al. (2014), where lamb flavour was noticed by the sensory panel although BCFA levels detected in the present study were very low in fat extracts of muscle tissue.

A lack of significant results concerning correlations could be due to other substances besides the three BCFAs tested being involved in lamb flavour. Another possibility would be a different fatty acid composition in subcutaneous as opposed to intramuscular fat as observed for some fatty acids and reviewed by Wood et al. (2008). Differences in the fatty acid composition of subcutaneous and intramuscular fat with regard to BCFA remain unclear but might be an interesting objective for further studies.

\section{Conclusions}

Differences in concentrations of 4-Me-8:0, 4-Et-8:0 and 4Me-9:0 were detected in subcutaneous adipose tissue of different crosses. For fat extracts from muscle tissue, concentrations of the fatty acids investigated could not be quantified. In adipose tissue samples significant correlations were found between BCFAs. Correlations between the amount of BCFAs in adipose tissue and meat sensory traits were not significant, possibly because of other substances involved or differences in the fatty acid composition of intramuscular fat and adipose tissue.

Acknowledgements. The authors thank the laboratory teams of the Institute of Animal Science and the Institute of Food Chemistry of the University of Hohenheim. K. F. Schiller was supported by the H. Wilhelm Schaumann Stiftung, Hamburg, Germany.

Edited by: K. Wimmers

Reviewed by: two anonymous referees

\section{References}

Brennand, C. P. and Lindsay, R. C.: Distribution of volatile branched-chain fatty acids in various lamb tissues, Meat Sci., 31, 411-421, 1992.

Busboom, J. R., Miller, G. J., Field, R. A., Crouse, J. D., Riley, M. L., Nelms, G. E., and Ferrell, C. L.: Characteristics of Fat from Heavy Ram and Wether Lambs, J. Anim. Sci., 52, 83-92, 1981.

Chillard, Y., Ferlay, A., Rouel, J., and Lamberet, G.: A review of nutritional and physiological factors affecting goat milk lipid synthesis and lipolysis, J. Dairy Sci., 86, 1751-1770, 2003.

Diedrich, M. and Henschel, K.-P.: The natural occurrence of unusual fatty acids - Part 1: Odd numbered fatty acids, Food/Nahrung, 34, 935-943, 1990.

Duckett, S. K. and Kuber, P. S.: Genetic and nutritional effects on lamb flavour, J. Anim. Sci., 79, E249-E259, 2001.

Duncan, W. R. and Garton, G. A.: Differences in the proportions of branched-chain fatty acids in subcutaneous triacylglycerols of barley-fed ruminants, Br. J. Nutr., 40, 29-33, 1978.

Ha, J. K. and Lindsay, R. C.: Distribution of volatile branched-chain fatty acids in perinephric fats of various red meat species, Leb. Technol., 23, 433-440, 1990.

Henseler, S., Preuss, S., and Bennewitz, J.: Fleischerzeugung mit Merinolandschaf-Gebrauchskreuzungen - 2. Mitteilung, sensorische Analyse und Zusammenführung der Ergebnisse in einem Index, Züchtungskunde, 86, 104-115, 2014 (in German).

Kaffarnik, S., Preuß, S., and Vetter, W.: Direct determination of flavour relevant and further branched-chain fatty acids from sheep subcutaneous adipose tissue by gas chromatography with mass spectrometry, J. Chromatogr. A, 1350, 92-101, 2014.

Lindsay, R. C.: 11. Flavours, in: Food Chemistry, 3rd Edn., edited by: Fennema, O. R., Karel, M., Sanderson, G. W., Tannenbaum, S. R., Walstra, P., and Whitaker, J. R., 752 pp., Marcel Dekker Inc., New York, USA, 1996.

Miller, G. J., Field, R. A., and Agboola, H. A.: Lipids in subcutaneous tissues and longissimus muscles of feedlot and grass-fed ewes, J. Food Qual., 9, 39-47, 1986.

Prescott, J., Young, O., and O'Neill, L.: The impact of variations in flavour compounds on meat acceptability: a comparison of Japanese and New Zealand consumers, Food Qual. Prefer., 12, 257-264, 2001.

Priolo, A. P., Icol, D. M., and Gabriel, J. A.: Effects of grass feeding systems on ruminant meat colour and flavour: A review, Anim. Res., 50, 185-200, 2001.

Resconi, V. C., Campo, M. M., Montossi, F., Ferreira, V., Sañudo, C., and Escudero, A.: Relationship between odour-active com- 
pounds and flavour perception in meat from lambs fed different diets, Meat Sci., 85, 700-706, 2010.

Rhee, K. S. and Ziprin, Y. A.: Identification and acceptance of lamb versus beef and pork by consumers and experienced sensory panelists, J. Muscle Foods., 7, 243-253, 1996.

Sañudo, C., Enser, M. E., Campo, M. M., Nute, G. R., María, G., Sierra, I., and Wood, J. D.: Fatty acid composition and sensory characteristics of lamb carcasses from Britain and Spain, Meat Sci., 54, 339-346, 2000.

Watkins, P. J., Rose, G., Salvatore, L., Allen, D., Tucman, D., Warner, R. D., Dunshea, F. R., and Pethick, D. W.: Age and nutrition influence the concentrations of three branched chain fatty acids in sheep fat from Australian abattoirs, Meat Sci., 86, 594 $599,2010$.
Wong, E., Nixon, L. N., and Johnson, C. B.: Volatile Medium Chain Fatty Acids and Mutton Flavour, J. Agric. Food Chem., 23, 495498, 1975.

Wood, J. D., Enser, M., Fisher, A. V, Nute, G. R., Sheard, P. R., Richardson, R. I., Hughes, S. I., and Whittington, F. M.: Fat deposition, fatty acid composition and meat quality: A review, Meat Sci., 78, 343-358, 2008.

Young, O. A. and Braggins, T. J.: Sheepmeat odour and flavour, in: Flavour of Meat, Meat Products and Seafood, edited by: Shahidi, F., Blackie Academic and Professional, London, UK, 1998.

Young, O. A., Lane, G. A., Priolo, A., and Fraser, K.: Pastoral and species flavour in lambs raised on pasture, lucerne or maize, $\mathrm{J}$. Sci. Food Agric., 83, 93-104, 2003. 